\title{
Elaboration and intuitions of disagreement
}

\section{forthcoming in Philosophical Studies}

Alex Davies (alex.stewart.davies@gmail.com)

\begin{abstract}
Mark Richard argues for truth-relativism about claims made using gradable adjectives. He argues that truth-relativism is the best explanation of two kinds of linguistic data, which I call: true cross-contextual reports and infelicitous denials of conflict. Richard claims that such data are generated by an example that he discusses at length. However, the consensus is that these linguistic data are illusory because they vanish when elaborations are added to examples of the same kind as Richard's original. In this paper I defend the reality of Richard's data. I show that, in trying to make their point, Richard's critics have focused upon examples that are similar in some respects to Richard's original but which lack a crucial feature of that original. When we ensure that this feature is in place, elaborations which make the data vanish are not possible. Richard's critics therefore fail to show that the data generated by Richard's original example are illusory.
\end{abstract}

\section{Introduction}

Richard (2004, 2008) argues for truth-relativism about claims made using gradable adjectives i.e. the thesis that the truth of a claim made using a gradable adjective is relative to a context of assessment. ${ }^{1}$ Truth-relativism is not just the thesis that the truth of a sentence is relative to a context of use. The idea is that a claim or assertion - the utterance of a sentence in a context of use-can be true relative to one context for assessing the truth of that claim or assertion and false relative to another. Richard argues that truth-relativism is the best explanation of two kinds of linguistic data, which I will call true cross-contextual reports and infelicitous denials of conflict. Although Kennedy (2013) accepts that these data are real, the consensus is that these data are not real (cf. (Garcia-Carpintero, 2008;

1 I go along with Garcia-Carpintero (2008) and Marques and Garcia-Carpintero (2014) in this interpretation of Richard (2004, 2008). But I doubt that this interpretation is correct. My doubt arises for reasons acknowledged by Garcia-Carpintero (2008, p. 147). Yet, whatever Richard's intended position actually is, it's clear what data he uses to defend his position and this paper is about that data. 
Hawthorne, 2004; Marques \& Garcia-Carpintero, 2014; Schaffer, 2011; Stanley, 2005)). The consensus is based on a recurring objection, which I will call the elaboration objection; roughly, when one of the parties to the purported disagreement is allowed 'to explain himself better' (Garcia-Carpintero 2008 p.149) then the data waver (ibid) or vanish (Marques \& Garcia-Carpintero, 2014, p. 714). In this paper, I defend the reality of these linguistic data against the elaboration objection. I argue that the kind of explanation required to make the data vanish cannot be provided in the example Richard originally used to generate the data. This is true even though it is also true that the explanation can be used to make the data disappear in the examples discussed by Richard's critics. In other words, Richard's original example is relevantly different from the examples used by his critics. Once we recognize this, and once we recognize that his example blocks the elaboration objection, we should acknowledge that his data are not shown to be illusory by the observations of his critics.

I proceed in the following stages. In sections 2 and 3, I describe in greater detail both the elaboration objection and the data used by Richard to defend truth-relativism. In section 4, I explain why the elaboration objection cannot be applied to Richard's original example, even though it can be applied to the examples discussed by his critics. In section 5, I explain why Richard's critics have failed to replicate the right features of Richard's original example: they abide by Richard's account of why his example generates the relevant linguistic data and hence of how examples of the same kind can be produced. But Richard's account is incorrect. In section 6 I provide an improved account. I show that if 
we produce further examples using this improved account then we will produce further examples which are not susceptible to the elaboration objection. In section 7 , I give some reason to believe that the data can be generated for a much wider range of expressions than gradable adjectives. In section 8 , I contrast the account of section 6 with another (put forward by Barker (2013) and Kennedy (2013)) with which it might, but should not, be confused.

Before we begin, I hasten to add that none of this is intended to show that truth-relativism is true. It's possible that alternative accounts of the relevant data are available. After all, although Marques and Garcia-Carpintero (2014) do not believe that Richard's data are real, they do think that such data can be generated with other expressions (viz. predicates of personal taste). They nonetheless think that a non-truth-relativist account of that data is superior. I see no reason why such an account could not be provided for Richard's data as well. This paper is about the reality of the data and not about what it implies.

\section{True cross-contextual reports and infelicitous denials of conflict}

Gradable adjectives are adjectives which admit intensifiers (e.g. "very", "really") and sometimes maximizers (e.g. "completely", "totally"). Richard (2004, p. 218) reminds us that gradable adjectives are widely thought to be context sensitive. What is tall for a Brit is not tall for a Dane and what is rich for a philosophy professor is not rich for an oil tycoon. It seems that for a gradable adjective " $F$ ", what is F depends upon a contextually supplied comparison class (e.g. Brits, Danes, philosophy professors or oil tycoons). One can account 
for this by identifying the semantic value of a gradable adjective with a function from objects to truth values such that an object maps to true just in case it passes a threshold on a scale, where the scale depends on the adjective in question (e.g. height, wealth etc.) and the threshold is (something like) the average of a contextually supplied comparison class (e.g. the average height of a Brit). ${ }^{2}$ I presume this account in what follows. There are, of course, other accounts of the semantic value of gradable adjectives that explain a greater range of data. But the observations and arguments of this paper are unaffected by the choice of account that we presume, provided that the account we presume at least explains the data described in this paragraph. With this in mind, Richard asks us to consider the following two assertions:

(1) (Didi in her context C1): Mary's rich.

(2) (Naomi in her context C2): Mary is not rich at all.

Richard tells us the following about C1 and C2:

Suppose, to take an example, that Mary wins a million dollar lottery. Didi is impressed, and remarks to a friend 'Mary's rich.' Naomi, for whom a million dollars is not really all that much, remarks in a conversation disjoint from Didi's, 'Mary is

2 Most analyses of gradable adjectives do not attribute this semantic value directly to the adjective. Rather, the adjective is assigned a function from objects to degrees which combines with degree morphology to produce something like the semantic value described above. The positive form of an adjective (which does not combine with any explicit degree morphology) combines with an aphonic morpheme to produce something like the semantic value described above. See, for example, (Cresswell, 1977) and (Kennedy, 1999). 
not rich at all'. Suppose the salient comparison class is the same in both cases. (Both are taking New Yorkers to be the relevant field of comparison.) Suppose that there is no difference between the two conversations in the point of assessing people as rich or otherwise. (Each conversation began with the observation that some wealthy person doesn't deserve to be rich, and each of the women is now idly assessing people as rich or otherwise, and then assessing whether the rich ones deserve their wealth.) (Richard, 2004, p. 218)

Richard supposes-as will we-that 'Mary is rich' is true when assessed relative to the standards operative in $\mathrm{C} 1$ and that 'Mary is not rich at all' is true when assessed relative to the standards operative in C2. He also makes two claims about (1) and (2). Firstly, he (ibid) claims that 'It seems to most of us that Naomi is contradicting Didi.' Following GarciaCarpintero (2008, p. 145), I will interpret this claim as meaning that denials of conflict by either Didi or Naomi are infelicitous; i.e. using “?” to indicate infelicity:

(3) (Didi, in C2, responding to Naomi's assertion): (?) That does not contradict what I said. $^{3}$

Secondly, Richard claims that cross-contextual (disagreement) reports are true as applied to (1) and (2). For example:

3 Garcia-Carpintero also considers felicitous retractions. I set them aside for ease of exposition but I assume that what's said here for infelicitous denials of conflict also applies to felicitous retractions. 
(4) (Richard in his third context): Didi and Naomi disagree. Didi thinks that Mary is rich but Naomi does not.

It is in order to account for the infelicity of denials of conflict and the truth of crosscontextual reports, as made of (1) and (2), that Richard endorses truth-relativism. If an assertion can be true relative to one context of assessment and false relative to another then despite the difference in the truth value of 'Mary is rich' in $\mathrm{C} 1$ and C2, firstly, the content Didi expresses can be inconsistent with the content expressed by Naomi, and secondly, Richard can make a true cross-contextual report about Didi and Naomi in his context.

\section{The elaboration objection}

Recall that the elaboration objection is roughly this: when one of the parties to the purported disagreement is allowed to explain himself better then the relevant linguistic data vanish. Several philosophers have raised this objection but, for the moment, we will focus on Garcia-Carpintero (2008). Although he is targeting Richard's data, GarciaCarpintero does not level the elaboration objection against the particular example discussed by Richard i.e. (1) and (2). He focuses instead on what he evidently considers to be an example of the same kind:

(5) (A, assuming Bill is $1.96 \mathrm{~m}$ tall, informally discussing the height of basketball players): Bill is short. 
(6) (B, assuming Bill is $1.96 \mathrm{~m}$ tall, discussing the height of basketball players with basketball coaches, after concluding from careful study that players shorter than 1.9587 are not ideal for the game): Bill is not short.

Even though 'Bill is short' is true in A's context and 'Bill is not short' in B's context (we may suppose), the assertions seem to allow for an infelicitous denial of conflict and a true crosscontextual report:

(7) (A, in B's context, responding to B's assertion): (?) That does not contradict what I said.

(8) $(C$, in some third context): A and B disagree. A thinks that Bill is short but B does not.

However, if we elaborate in the following ways then these appearances disappear:

(9) (A in B's context, responding to B's assertion): That does not contradict what I said. I was just saying that Bill is short for a basketball player on rough estimates for the purposes of coffee talk; we were not contemplating your levels of precision; thus I was not wrong.

(10) (D, in context C3, responding to C's cross-contextual report): That's not true. A was saying Bill is short for a basketball player on rough estimates for the purposes of coffee talk but B was saying Bill is not short for a basketball player for the 
purposes of talking with basketball coaches, after concluding from careful study that players shorter than 1.9587 are not ideal for the game.

Less roughly then, the elaboration objection is as follows. Suppose that " $F$ " is a gradable adjective and " $\mathrm{O}$ " is a name that has a context-insensitive referent. Now consider two utterances made in different contexts: one utterance of "O is F" and the other of "O is not F." Suppose that each utterance is true when assessed relative to the standards operative in its own context. Suppose that "F" has the same contextually specified comparison class in each context. The elaboration objection is this: although the appearances of an infelicitous denial of conflict and a true cross-contextual report can be generated for these two utterances, those appearances vanish when the report and the denial are elaborated upon in the ways exemplified in (9) and (10) i.e. by drawing attention to a divergence of purposes across the two contexts. The appearances are therefore mere appearances and so cannot constitute evidence for a semantic theory.

\section{We cannot apply the elaboration objection to Richard's example}

Garcia-Carpintero's chosen example strongly resembles Richard's original. However, although we can apply the elaboration objection to Garcia-Carpintero's example, if we take careful note of how Richard describes the two contexts of his example-C1 and $\mathrm{C} 2$-we will find that we cannot apply the elaboration objection to Richard's original. For in Richard's original, the contexts $\mathrm{C} 1$ and $\mathrm{C} 2$ do not differ in the purposes pursued: Richard stipulates that they are the same. See again the extended quotation from Richard in section 
2. In particular, this part:

Suppose that there is no difference between the two conversations in the point of assessing people as rich or otherwise. (Each conversation began with the observation that some wealthy person doesn't deserve to be rich, and each of the women is now idly assessing people as rich or otherwise, and then assessing whether the rich ones deserve their wealth.) (Richard, 2004, p. 218)

But in order to formulate elaborations in the ways exemplified in (9) and (10), we need a divergence of purposes across the contexts.

Perhaps, rather than drawing attention to divergent purposes, we could focus on the mere fact that Naomi and Didi clearly view wealth in different ways: even for a fixed comparison class, they place the threshold of wealth that one must surpass in order to be rich at different points on the scale of wealth. This could be a relevant difference between the two contexts - in fact, this seems to be the only difference in Richard's example. Perhaps, simply on account of this, the intuitive truth of (4) can be made to disappear and the intuitive infelicity of (3) also. But this would be surprising. It's hardly a revelation that Naomi and Didi differ in this respect. Richard is explicit about the difference. So if the difference sufficed to undermine the report's truth and the denial's infelicity, it would be strange that Richard's paper was ever published - reviewers would surely have denied the reality of Richard's data. Consider the following: 
(11) (Didi in Naomi's context, responding to Naomi's assertion): (?) That does not contradict what I said. I was just saying that Mary is rich in the sense that she's got a lot more disposable income than most people in the world have; we were not contemplating your standards of wealth; thus I was not wrong.

(12) (Me, in Richard's context, responding to Richard's cross-contextual report): (?) That's not true. Didi was saying that Mary is rich in the sense that she's got a lot more disposable income than most people in the world but Naomi was saying that Mary is not rich in the sense that she's not got as much disposable income as Naomi has.

Insofar as what gives rise to the conflict between Didi and Naomi is that they disagree about where to place the threshold one must surpass in order to qualify as rich on a scale of wealth, attempts to draw attention to this can only sound like restatements of Didi and Naomi's disagreement rather than a means to show that the disagreement is merely verbal. Surely, at one time or another, each of us has been engaged in a dispute with someone only to have a well-meaning third-party try to reveal the dispute to be baseless by drawing attention to a divergence in the use of a term by the parties to the dispute, and yet, the attempt falls flat because it merely reveals that the third-party doesn't really understand the depth of the disagreement. Given Richard's description of $\mathrm{C} 1$ and $\mathrm{C} 2$, this is how we should think of (11) and (12), and if we do then (11) and (12) will strike us as infelicitous: they seem to betray a misunderstanding by, in the one case, Didi and, in the 
other, me. Certainly, sometimes pointing out a divergence in the use of an expression by two parties who seem to disagree can thwart the impression that they disagree. But not always and not in Richard's original example.

This same problem for the elaboration objection arises for all other attempts to apply it: whereas Richard's original example involved a stipulation that there is no divergence of purpose across the two contexts, when critics try to show that the relevant kind of crosscontextual disagreement is illusory, they describe contexts either for which there is no stipulation of common purpose or for which there is a stipulation of divergent purposes (cf. (Hawthorne, 2004, p. 104; Marques \& Garcia-Carpintero, 2014, pp. 712-714; Schaffer, 2011, p. 213; Stanley, 2005, pp. 55-56).

\section{Richard's mistaken account}

Why would critics of truth-relativism target examples that are significantly different from the one actually employed by Richard? That's easily explained. Richard proposes an account of how to build examples of the same kind as his original. He (2004, p. 229) proposes that in the semantic value of a gradable adjective, it's not just the comparison class which is context-sensitive. He proposes that even once the comparison class has been fixed, the precise threshold for that comparison class is still to be settled by contextual factors: you don't fix one by fixing the other. Moreover, he (ibid, pp.229-230) proposes that whereas the comparison class is fixed solely by the speaker's intention, the threshold can be "negotiated" in context. It can be modified by providing, 'examples, argument, 
mutually agreeable stipulation, and so on.' (Richard, 2004, p. 227). On Richard's account, it is because the threshold can be negotiated in context that we can generate a true crosscontextual report and an infelicitous denial of conflict for his example. This account implies that any gradable adjective, regardless of the contexts in which it is employed, should give rise to true cross-contextual reports and infelicitous denials of conflict. This, it seems, is why Garcia-Carpintero and company have supposed it acceptable to criticize Richard (or at least, a truth-relativist who motivates her position by appealing to truth cross-contextual reports and infelicitous denials of conflict) by using examples that differ from Richard's original but which nonetheless include a gradable adjective used in two contexts with the same comparison class. They think such examples are of the same kind as Richard's original. In working with such examples, these critics demonstrate that, insofar as Richard has an example that gives rise to true cross-contextual reports and infelicitous denials of conflict, it doesn't give rise to these phenomena for the reasons Richard thinks it does. But they do not show that Richard's example does not give rise to these data.

\section{An alternative account: permissive contexts}

If Richard's account doesn't correctly explain how we can produce more examples like his original, is there a better alternative account that does? Let's see. Here's what we know about Richard's original example. Firstly, we know that the purposes of the interlocutors in each context (C1 and C2) are stipulated to be the same. Secondly, we know that those purposes have been stipulated to be idle; i.e. in each context there are no linguistic, 
instrumental or moral reasons for using "rich" with a certain threshold of wealth that one must surpass to qualify as rich. This means, the tools of contextual negotiation listed by Richard ('examples, argument, mutually agreeable stipulation, and so on') cannot be marshalled to show that one way of using "rich" is the correct one for either context-any argument about that is doomed to have no resolution. Thirdly, although no factor in either context makes it the case that occupants of the context ought to use the expression one way or another, the occupants in the different contexts nonetheless have different preferences for how to use the gradable adjective.

In light of what we know, here's an alternative account of the operative features of Richard's example. In a given context, there are various normative factors which bear upon whether one should use an expression in a particular way in that context. These factors might be linguistic: e.g. its part of the meaning of "rich" in English that you cannot use it to be mean the same as "swan." These factors might be instrumental: e.g. if a photographer gives you instructions for finding green leafs to be used as props in a colour photography project then, ceteris paribus, you should use "green" so that something is green only if it is visibly green on its surface (rather than green underneath a coat of red paint) (c.f. (Travis, 2008)). These factors might be moral: e.g. it might be incorrect to apply the word "man" to a person who honestly self-identifies as a woman if it is morally wrong to do so (cf. (Saul, 2012) and (Diaz-Leon, forthcoming)). But it's possible that, in a given context, the sum of factors that bear upon how an expression ought to be employed in that context does not require that occupants of that context use the expression in one of several 
different ways. I will call such contexts permissive. In Richard's original example, we find two contexts which are such that, firstly, both are permissive with respect to the threshold of wealth for "rich" when used with a comparison class of New Yorkers and, secondly, occupants of the contexts nonetheless have different preferences with respect to how to set this threshold. An alternative account of the operative features of Richard's example is that the operative features are the two features just listed: the two contexts are both permissive with respect to the threshold for being rich and participants in each context have diverging preferences with respect to this threshold. On this account, Richard's example is a special case of a very familiar kind of situation. The multifarious normative factors that bear upon what one should do in a given situation just don't tip the balance in favour of one of several options. So one can exercise one's preferences in choosing between those options without violating any normative principle governing what one ought to do.

If this account is correct then we should be able to use it to generate further examples like Richard's original that are not susceptible to elaboration objections. This does indeed seem to be possible. Suppose that two teenage girls, Sue and Tina, are in different contexts (C3 and C4) and in each context each is idly assessing whether or not Tina's boyfriend is short. Let's suppose that the comparison class in both cases is the set of American teenage boys. This leaves open a host of matters which bear upon who is an American boy and what their heights are: which are the true Americans; which boys are really better thought of as men (on account of emotional maturity or puberty or something else?); and so on. Sue and Tina take different views on how these matters bear upon the threshold for being short for 
an American teenage boy. But, let's suppose, nothing - no linguistic, instrumental or moral factor-in either C3 or C4 rationally requires them to take one view on this matter over another. Now consider the following two assertions:

(13) (Sue in C3): Tina's boyfriend is short.

(14) (Tina in C4): My boyfriend is not short.

It seems that a denial of conflict by Sue, directed against (14), would be infelicitous and that a true cross-contextual report can be made of (13) and (14):

(15) (Sue, in C3, responding to Tina's assertion): (?) That does not contradict what I said.

(16) (Richard in his third context): Sue and Tina disagree. Sue thinks that Tina's boyfriend is short but Tina doesn't think that he's short

However, as with Richard's original example, elaborations which appeal to a divergence of purpose in C3 and C4 cannot be used to show (15) and (16) to be illusory data because there simply is no divergence of purpose between $C 3$ and $C 4$ that can be cited to do the job. Moreover, modified elaborations which seize upon the difference in how Sue and Tina think of being short for an American teenage boy will only amount to restatements of the disagreement: they will not reveal it to be merely verbal. 
The example discussed by Garcia-Carpintero (viz. (5) and (6)) does not include two permissive contexts. Each of the two contexts he discusses includes factors (purposes) that rationally require occupants of the respective contexts to use "short" with a particular threshold. It's by stating these purposes that Garcia-Carpintero creates the impression that "short" is being used differently in each context (compare this with the way Richard achieves the same effect in the extended quotation in section 2). Similar things can be said for the other examples against which the elaboration objection has been levelled by Hawthorne, Marques and Garcia-Carpintero, Schaffer, and Stanley: either divergent, nonpermissive purposes are stipulated or else no single idle purpose is stipulated. In the former case, elaboration objections are not blocked by permissive contexts because there aren't any. In the latter case, elaboration objections are not blocked by permissive contexts because, without stipulations that make clear the permissiveness of the contexts, it's possible to presuppose a non-permissive context in the formulation of the elaboration and thereby make the elaboration felicitous. This is so even though one wouldn't be able to do this if it had already been made explicit that the contexts are permissive. For instance, consider the following example from Schaffer (2011, p. 213):

(17) Ann: Licorice is tasty.

(18) Ben: No, licorice is not tasty.

(19) Ann: Listen, I was just saying that I like it.

(19) could be an elaboration on a denial of conflict between (17) and (18). As such, (19) is 
perfectly legitimate for all that we have been told about what Ann's purposes were in (17). In fact, (19) seems to provide us with information about what Ann's purposes were in (17). However, if it had already been clear what Ann's purposes were in (17), and if it had already been clear that she was not just trying to say that she liked licorice but instead had (in the sense described above) a mere idle purpose, then (19) would be problematic. Suppose, for example, that Ann and Ben commonly get into a playful (but honest) argument about whether licorice is tasty which neither of them ever wins but which is fun to have anyway. Suppose it was obvious when Ann uttered (17) that she was instigating this kind of exchange. However, because someone walks past that makes her embarrassed to engage in that kind of exchange (e.g. her boss), she utters (19) to pretend as though she is far too mature to engage in such a childish conversation. If this were all apparent to Ben, he could object to (19) qua denial of conflict. When she uttered (17), Ann was not just saying that she likes licorice; not if that is supposed to mean that Ben has misunderstood her purposes in uttering (17) and hence spoke with her at cross purposes when he uttered (18). Thus, if the context of (17) were explicitly permissive, the elaborated denial of conflict in (19) could not be made felicitously.

Such is the importance of being explicit about permissive contexts. Whether they stipulate non-permissive contexts, or fail to stipulate permissive contexts, because the examples provided by Richard's critics differ in this respect from Richard's original, they cannot be used to show that the intuitions produced in Richard's original are illusory. ${ }^{4}$

4 Notably, the example which Marques and Garcia-Carpintero (2014, p. 701) think does give rise to true cross-contextual reports is an example in which it has been stipulated that the context is permissive. 


\section{Other expressions: e.g. comparative adjectives}

It seems that contexts which are permissive with respect to the threshold for being $\mathrm{F}$ (where " $\mathrm{F}$ " is a gradable adjective, used with a particular comparison class) allow true cross-contextual reports and infelicitous denials of conflict. Do we get the same effect with contexts that are permissive with respect to other context-sensitive features of linguistic expressions? I think we do. Let's consider the comparative adjective "taller than." The thing about comparative adjectives is that if we can show that an assertion made using "A is F-er than $\mathrm{B}$ " and an assertion made using "A is not F-er than $\mathrm{B}$ " can give rise to true cross-contextual reports and infelicitous denials of conflict (even though each sentence is true relative to the standards operative in its own context of use) then this cannot be explained by appeal to indeterminacy or vagueness in the threshold for being $\mathrm{F}$-contrary to what Richard (2004, pp. 226-227) seems to suggest. This is because the location of that threshold doesn't affect the relative positions of A and B on the relevant scale but it is their relative positions that matter for the truth of claims like "A is F-er than B." This is presumably why, although Kennedy (2013, p. 275) accepts what Richard says about gradable adjectives, he does not think that the same phenomena can arise for comparative adjectives. ${ }^{5}$ However, as we'll now see, the phenomena can arise for comparative adjectives when we replicate the relevant features of Richard's original example. Consider the following:

5 Kennedy denies that comparative adjectives allow faultless disagreement when those comparative adjectives have a dimensional-rather than an evaluative-reading. The example discussed in this section clearly involves the use of a comparative adjective with a dimensional reading. 


\section{Height Banter}

During the course of a day, in some sense, your height changes. This happens because the spinal discs between your vertebrae are largely made of water. When you place weight on the disks in your back (as when you are standing or sitting upright), they compress (over the course of several hours). But when you're lying down, they expand. Ana, Bea, Cat and Dee are four competitive girls. They compete over everything: who can fit the most gob-stoppers in her mouth, who can jump the furthest etc. Suppose that Ana recently broke a leg and for this reason spends most of each day lying down. When they stand against a wall, Ana's height is a centimetre or so higher than Cat's. Suppose that if Ana and Cat had been lying down all day, then Cat would be taller than Ana. Being competitive girls, each girl wants to be taller than the other. For that reason, Cat adopts the view that the proper way to compare two persons' heights is to ensure that they have both been lying down for the same amount of time prior to measurement. For the same reason, Ana adopts the view that the proper way to compare two persons' heights is to stand them against a wall and measure their heights - regardless of whether one of them has been lying down recently. Finally, suppose that Bea is a friend of Ana's who agrees with Ana about the proper way to measure relative height and Dee is a friend of Cat's who agrees with Cat about the proper way to measure relative heights. Now, suppose that in one context, Ana and Cat are talking about whether Ana or Cat is taller, and in another context, Bea and Dee are talking about whether 
Ana or Cat is taller. In each context, there's nothing but banter going on: these are permissive contexts. Nothing in either context settles how relative height is to be understood in that context. In the first context, Ana says, "I am taller than you," and in the second context, Dee says, "Ana is not taller than Cat."

Just as in Richard's original "rich" example, an attempted denial of conflict by Ana would be infelicitous:

(20) (Ana in Dee's context, responding to Dee's assertion): (?) That doesn't contradict what I said.

Similarly, Richard can make a true cross-contextual report by saying:

(21) (Richard, in some third context): Ana and Dee disagree. Ana thinks that she is taller than Cat but Dee thinks she isn't.

Moreover, for now familiar reasons, elaborations won't change this: there are no divergent purposes that can be appealed to which require use of "taller than" in a particular way in either Ana or Dee's context and hence which could be used to formulate elaboration objections against (20) and (21).

This gives us reason to believe that the linguistic data generated by Richard's original 
example are not dependent upon vagueness: i.e. indeterminacy in exactly where the threshold on the scale of a gradable adjective lies. The comparison class for the comparative adjective or some other contextual feature of the adjective must be responsible for the data generated by Height Banter. But if (contra Richard) vagueness is not a precondition for generating the relevant data then there's reason to believe that a range of context-sensitive expressions (when used in the right contexts) could give rise to true cross-contextual reports and infelicitous denials of conflict-a range that extends beyond gradable adjectives. I am not sure how wide this range will be. It certainly doesn't seem to encompass indexicals and demonstratives (consider analogues of (1) and (2) with the sentence 'Mary is her'). But it seems that it could encompass prepositional phrases (e.g. “on the rug"), possessives (e.g. "John's book"), certain verbs (e.g. "harm”), quantifiers (e.g. "everyone"), some count nouns (e.g. "portion"), some mass nouns (e.g. "water") and perhaps others. For each of these expressions, we can find ways to draw distinctions that would imply differences in the extensions of such expressions. For example, we could distinguish between a conception of "on the rug" according to which meat wrapped in a sealed plastic bag on top of a rug is meat "on the rug" and a conception of "on the rug" according to which it is not. If employed in appropriately permissive contexts, it seems very likely that true cross-contextual reports and infelicitous denials of conflict will be forthcoming for assertions made using such expressions, where even though one assertion is made using a sentence and the other is made using that sentence's negation, each sentence is true relative to its own context of use. To show this convincingly we would have to consider the evidence that bears on the behaviour of each expression. Nonetheless, 
from our current standpoint we can certainly see how we could go about generating that evidence given our alternative account of the operative features of Richard's original example.

\section{Uncertainty}

Barker (2013) and Kennedy (2013) propose a common explanation of why an assertion of a sentence (that employs a vague predicate) and an assertion of that sentence's negation can generate an appearance of disagreement between the two asserters even though neither asserter is at fault in asserting what she does. I am concerned that this explanation might appear to be a version of the account that I have provided of why Richard's original (1) and (2) give rise to true cross-contextual reports and infelicitous denials of conflict. So in this closing section I will explain why this appearance is mere appearance: Barker and Kennedy's explanation is not a version of the account put forward in this paper. By contrasting Barker and Kennedy's ideas with my own, I hope to make more obvious some of the features of my account of the data discussed in this paper.

Barker (2013, pp. 247-249) and Kennedy (2013, p. 274) put forward what I will call the uncertainty account of faultless disagreement. ${ }^{6}$ According to the uncertainty account, the value of a context-sensitive parameter of a vague predicate in context is what it is because speakers agree that it has a particular value in that context: for Barker the parameter is the

6 I call this "the uncertainty account" because Barker and Kennedy speak as follows: they say that if two equally competent speakers diverge in their views about the value of a contextual parameter of an expression in context then there is "uncertainty" about the value. 
threshold of the predicate, for Kennedy the parameter is the dimension of evaluation of the predicate. On this account, all speakers are equal in their authority to determine the proper value of the relevant parameter in context. ${ }^{7}$ So if speakers diverge in their judgements about the correct value of the parameter in a context then there just is no unique correct value of the parameter in the context. So if one speaker asserts a sentence and the other speaker asserts its negation but that sentence includes a vague predicate with such a parameter, then the speakers can qualify as disagreeing without either being at fault (i.e. each can have said something true relative to her own value for the contextual parameter and neither need be mistaken in adopting the value she does).

The uncertainty account might be understood as describing a way in which a permissive context can be produced: permissive contexts are generated when two speakers disagree about the correct value of a particular kind of context-sensitive parameter of a vague predicate in context. If the uncertainty account is thus understood then the uncertainty account will appear to be a version of the idea that permissive contexts generate the data that have concerned us in this paper-albeit a version that is limited in scope to vague predicates. But for two reasons, the uncertainty account should not be understood as a version of the account put forward in this paper.

Firstly, the uncertainty account requires us to be constructivists about the norms governing

7 I think this assumption is incorrect. I strongly suspect that there is often (perhaps normally) an interesting politics to the settling of context-sensitive content in context. For example, see Davies' (forthcoming) study of one way in which a cross-examiner can control the contents of context-sensitive terms employed by a cross-examined witness. 
the correct value of a context-sensitive parameter of an expression in context (something Barker (2013, p. 250) explicitly acknowledges). It requires us to suppose that the norms are constituted by agreement between different users of the expression (in context). Insofar as there is no agreement, no norm dictates with which parameter value the expression ought to be employed in context. But nothing about my appeal to permissive contexts requires constructivism. Whether norms constrain the correct way to use an expression in a context to such an extent that there cannot be divergent faultless assignments of values to a context-sensitive parameter in the context is a matter that is, it seems, separate from the matter of what constitutes the norms. It is consistent with the proposed account of true cross-contextual reports and infelicitous denials of conflict that two interlocutors can diverge in their judgements about the correct value to assign to a context-sensitive parameter of an expression in context and both of them be at fault. ${ }^{8}$ The fact of disagreement does not, on this view, protect them from being at fault. What matters is not whether they disagree about a special component of the semantic value of a given expression but instead whether the total context of use includes normative factors that make a particular value of the contextual parameter the correct value in that context. In this respect, the two accounts diverge. ${ }^{9}$

8 I say that this is consistent with the account, rather than that the account entails it, because the relevant norms might be constructivist. This would close the gap between the two accounts.

9 Barker (2013, p. 249) acknowledges one exception to this constructivism: he provides evidence that a speaker must be consistent in her use of a vague predicate during the same discourse and that this can undermine the appearance of faultless disagreement. Nonetheless, he does not acknowledge either the role played by normative contextual factors (as opposed to previous uses of the same vague predicate), or the role of contemporaneous context (as opposed to prior discourse) in fixing the correct value of a contextual parameter. 
Secondly, the uncertainty account repeats a mistake made by Richard. Richard claims that his original example generates true cross-contextual reports and infelicitous denials of conflict because the example included a kind of expression (a vague predicate) which has a context-sensitive parameter that is subject to "negotiation" (see section 5). So, regardless of what else might be going on in the context(s) of use, we can replicate those data by producing an example in which the same kind of expression is employed with a contextsensitive parameter that is subject to negotiation. It's because Richard's explanation of his data is insensitive to what more is going on in the context(s) of use that opponents have raised the elaboration objection against him: elaborations show that the data disappear when further features of the context are suitably modified. The uncertainty account is similarly insensitive to the wider context of use. It says that an asserter of a sentence and an asserter of that sentence's negation can disagree and be faultless in their assertions whenever the sentence includes a vague predicate and there is no consensus between the two asserters about the threshold (for Barker) or the dimension of evaluation (for Kennedy) of the predicate (albeit with the exception noted in footnote 9). However, given firstly that, in order to sustain an appearance of faultless disagreement, true cross contextual reports and infelicitous denials of conflict should be elicitable despite the sense that neither asserter is at fault, and given secondly that such data can be made to disappear with elaborations like those used against Richard unless it has been explicitly stipulated that the contexts of use are permissive, and given thirdly, that the uncertainty account provides no such stipulation, it follows that the elaboration objection will apply as much to Barker and Kennedy as it does to Richard. But the account of Richard's data 
described in this paper is not susceptible to the elaboration objection. This constitutes a second respect in which the uncertainty account of faultless disagreement diverges from the account of Richard's data put forward in this paper. The former is not a version of the latter. $^{10}$

\section{References}

Barker, C. (2013). Negotiating Taste. Inquiry: An Interdisciplinary Journal of Philosophy, 56(23), 240-27.

Cresswell, M. (1977). The semantics of degree. In B. Partee (Ed.), Montague Grammar (pp. 261-292). New York: Academic Press.

Davies, A. (forthcoming). How to Silence Content with Porn, Context and Loaded Questions. European Journal of Philosophy, Early View. Retrieved from http://onlinelibrary.wiley.com/doi/10.1111/ejop.12075/abstract

Diaz-Leon, E. (forthcoming). Woman as a Politically Significant Term: A Solution to the Puzzle. Hypatia.

Garcia-Carpintero, M. (2008). Relativism, Vagueness and What is Said. In M. GarciaCarpintero \& M. Kölbel (Eds.), Relative Truth (pp. 129-154). Oxford: Oxford University Press.

Hawthorne, J. (2004). Knowledge and Lotteries. Oxford: Clarendon Press.

10 For helpful comments on older versions of this paper, thanks are due to Solveig Aasen, Daniel Cohnitz, Dan Zeman, and the audiences at the KCL Language and Cognition Seminar, at the $8^{\text {th }}$ Semantics and Philosophy in Europe colloquium and at the Tartu Philosophy Department Summer Work-In-Progress Seminar. I thank an anonymous referee of this journal for pushing me to explain the relation of the ideas in this paper to work by Chris Barker and Chris Kennedy. 
Kennedy, C. (1999). Projecting the adjective: The syntax and semantics of gradability and comparison. New York: Garland.

Kennedy, C. (2013). Two Sources of Subjectivity: Qualitative Assessment and Dimensional Uncertainty. Inquiry: An Interdisciplinary Journal of Philosophy, 56(2-3), 258-277.

Marques, T., \& Garcia-Carpintero, M. (2014). Disagreement about Taste: Commonality Presuppositions and Coordination. Australasian Journal of Philosophy, 92(4), 701-723.

Richard, M. (2004). Contextualism and Relativism. Philosophical Studies, 119(1-2), 215-242.

Richard, M. (2008). When Truth Gives Out. Oxford: Oxford University Press.

Saul, J. (2012). Politically Significant Terms and Philosophy of Language: Methodological Issues. In A. Superson \& S. Crasnow (Eds.), Out from the Shadows: Analytic Feminist Contributions to Traditional Philosophy (pp. 195-216). Oxford: Oxford.

Schaffer, J. (2011). Perspective in Taste Claims and Epistemic Modals. In A. Egan \& B. Weatherson (Eds.), Epistemic Modality (pp. 179-226). Oxford: Oxford University Press.

Stanley, J. (2005). Knowledge and Practical Interests. Oxford: Oxford University Press.

Travis, C. (2008). Occasion-sensitivity: selected essays. Oxford: Oxford University Press. 